\title{
Healthcare productivity
}

\section{SUMMARY}

This article presents new estimates of publicly funded healthcare outputs, inputs and productivity for the period 1995 to 2008. These update the estimates published in Total Public Service Output and Productivity in June 2009 (ONS 2009a) by incorporating new methods to improve the measurement of output and input volumes and give the first results for 2008.

\section{Background}

ince ONS last published estimates

for multi-factor productivity growth

of UK publicly funded healthcare

in June 2009 (ONS 2009a, 2009b) it has implemented a number of improvements to the methods used to construct input and output volumes (see ONS 2010a, ONS 2010b and ONS 2010c). The way deflators are applied to construct volume measures of inputs have been updated, as have the cost weights used to construct output volumes following the inclusion of data for Wales. ONS has also published a Healthcare triangulation article (see ONS 2010d) to help users understand productivity estimates by providing additional contextual information, giving a wider picture than is possible in a single measure of healthcare productivity.

Incorporating these methods changes, along with new source data which allows the first productivity estimate for 2008 to be produced, has led to revisions from previously published data. In particular, the productivity estimate for 2007, which in ONS (2009a) was based on data for the financial year 2006-07, has been revised down. This is because newly available data for 2007-08 show that inputs rose more rapidly than output, reversing the previously published picture. However, in general revisions have increased output and reduced inputs, causing productivity estimates to be revised up in most years (see ONS 2010b for revision analysis).

Most of the methods and data for this article feed into the National Accounts.
However, the measure of UK output presented here differs from the National Accounts measure in that it is quality adjusted. The adjustment uses data on health outcomes and patient experience in England to create estimates of quality change for the UK.

\section{Productivity trends}

Latest estimates of healthcare productivity in the UK show that from 1995 to 2008 productivity fell by 3.3 per cent, an annual average decline of 0.3 per cent (see Figure 1). This is because over the whole period output grew by 69.3 per cent, an average annual increase of 4.1 per cent and inputs grew by 75.1 per cent, an average annual increase of 4.4 per cent. In 2008 productivity fell by 0.7 per cent, compared with a fall of 0.3 per cent in 2007 .

Within the whole period there were two distinct cycles of productivity change:

- after 1995 productivity fell slightly and remained broadly stable until 2001 when it picked up to just under the 1995 level. Average annual productivity growth over this period was 0.0 per cent

- from 2001 to 2008 productivity declined by 3.0 per cent with the exception of a brief pick up in 2005 and 2006. Input growth was generally more rapid than output growth during this period. This was due mainly to increases in the volume of goods and services, particularly in the category that includes goods and services 
Figure 1

Healthcare output, inputs and productivity, 1995-2008

\section{United Kingdom}

Index numbers, 1995=100

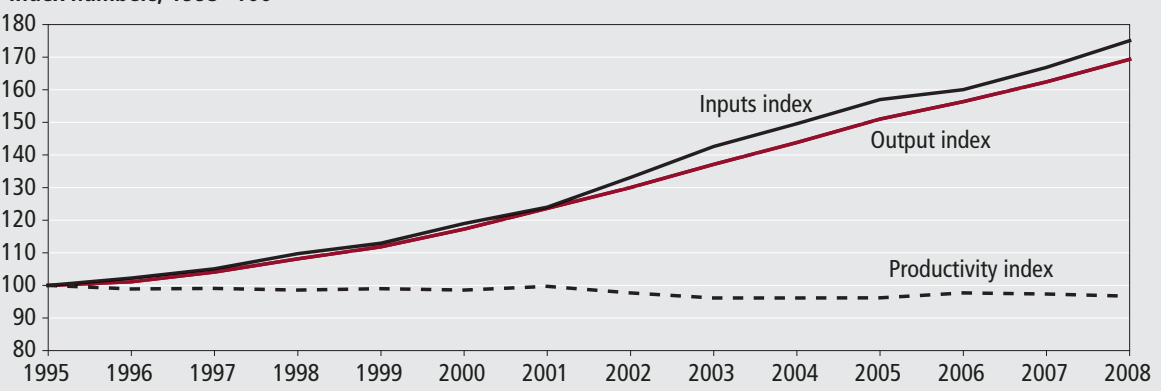

Source: Office for National Statistics

\section{Figure 2}

Healthcare output, 1995-2008

\section{United Kingdom}

Index numbers, 1995 $=100$

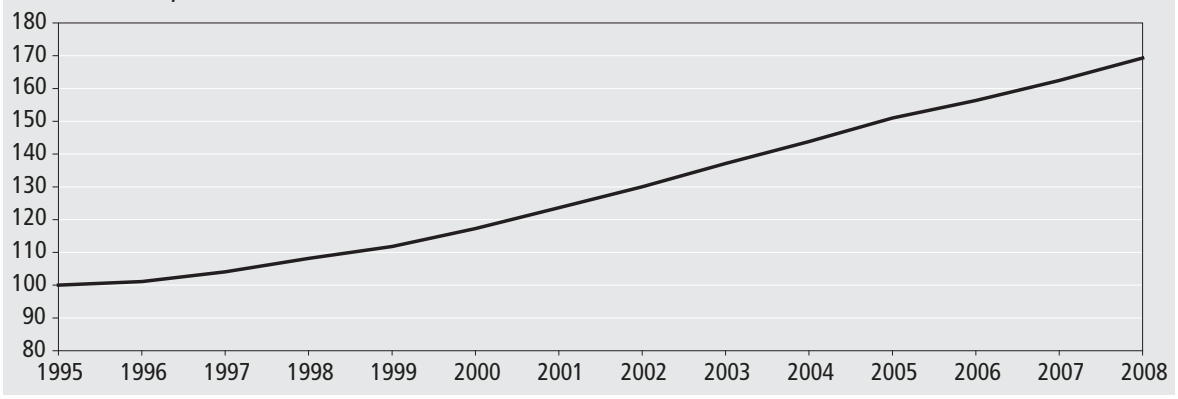

Source: Office for National Statistics

purchased by hospitals, those used in General Practitioner (GP) surgeries and healthcare purchased from outside the NHS

The pattern of productivity change in the UK is dominated by changes in England. The UK output pattern reflects:

- an increase of around 43 per cent in the quantity of Hospital and Community Health Services (HCHS) between 1995 and 2008

- an increase of just over 200 per cent in the volume of drugs prescribed by GPs between 1995 and 2008. Despite GP-prescribed drugs forming a small share of healthcare output, over the whole period they account for a contribution to output growth similar to that of Hospital and Community Health Services (HCHS), the largest component; and

- a positive growth in the composite measure of healthcare quality since 2002. The measure takes account of changes in post-operative survival rates, hospital waiting times, outcomes from primary medical care and patient experience
The UK inputs pattern reflects:

- an increase of around 40 per cent in the volume of labour used in the provision of publicly funded healthcare between 1995 and 2008; and

- a large increase in goods and services consumed in the production of healthcare services, which may reflect increased public resource into healthcare following the publication of the NHS plan in 2000 (NHS 2000). Some of the increase relates to greater expenditure on non-NHS procurement, which includes contracted-out services and Private Finance Initiatives (PFIs), but the main contribution to growth came from other 'goods and services' procured within the NHS. This category includes items ranging from bedding and bandages to electricity and water

Growth in output and inputs has been driven in general by an increase in the UK population, within which the proportion of older people has also been increasing. These changes have had a particular impact on publicly funded healthcare as older people place a greater demand on health services.

\section{Trends in output}

Latest estimates of change in healthcare output show that between 1995 and 2008, healthcare output grew by 69.3 per cent, an average annual increase of 4.1 per cent (Figure 2). Growth was highest from 2000 to 2005 , averaging 5.3 per cent a year. In 2008 growth was 4.2 per cent, compared with 3.9 per cent in 2007.

Key drivers of output change from 1995 to 2008 include:

- a rapid increase in the volume of drugs prescribed by GPs. Over the whole period, the volume of drugs increased by over 200 per cent, with growth averaging just under 9 per cent a year. This component accounts for just over one-sixth of output by expenditure weight

- a rise of around 43 per cent in the quantity of Hospital and Community Health Services (HCHS) over the whole period, or just under 3 per cent a year on average. HCHS is the largest component of output, accounting for around two-thirds of the total by expenditure weight

- an increase of just under 25 per cent in the quantity of Family Health Services (FHS), with growth averaging 1.7 per cent a year. This is the smallest output component, accounting for a little under one-sixth of the total

- a positive impact from healthcare quality in all years from 2002 onwards, following a slightly negative impact in 2001, when quality adjustment first enters into output estimates

Healthcare output has two components, quantity and quality - with quantity adjusted for quality. Change in the quantity of UK healthcare is assumed to be the same as the change in a cost weighted activity index covering most types of healthcare activity in England, Northern Ireland and Wales. Measured activities fall into one of three categories:

- Hospital and Community Health Services (HCHS), which include hospital inpatient, day case and outpatient episodes, distinguished by Health Resource Group (HRG)

- Family Health Services (FHS), which include GP and practice nurse consultations, publicly funded dental treatment and sight tests; and

- GP prescribing

Figure 3 summarises quantity growth for 


\section{Figure 3}

\section{Quantity measure of healthcare, 1995-2008}

\section{United Kingdom}

Index numbers, 1995=100

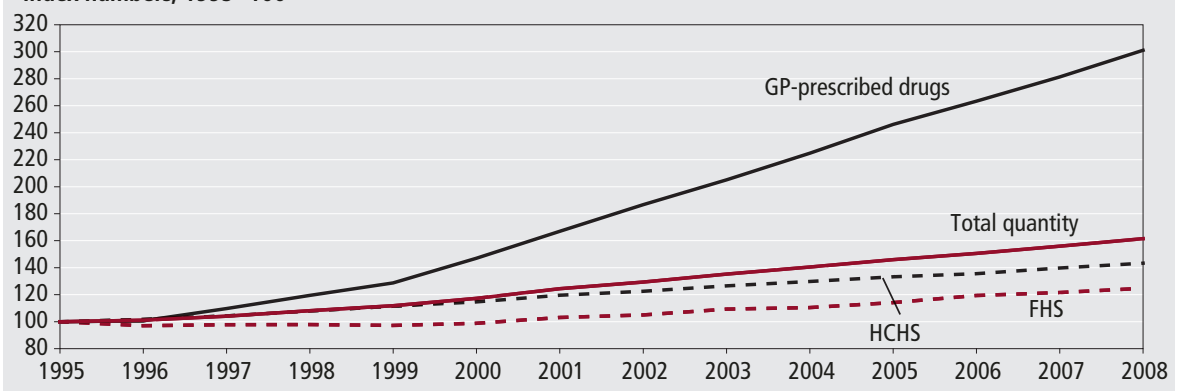

Source: Office for National Statistics

\section{Figure 4}

Healthcare quantity and output, 1995-2008

\section{United Kingdom}

Index numbers, 1995=100

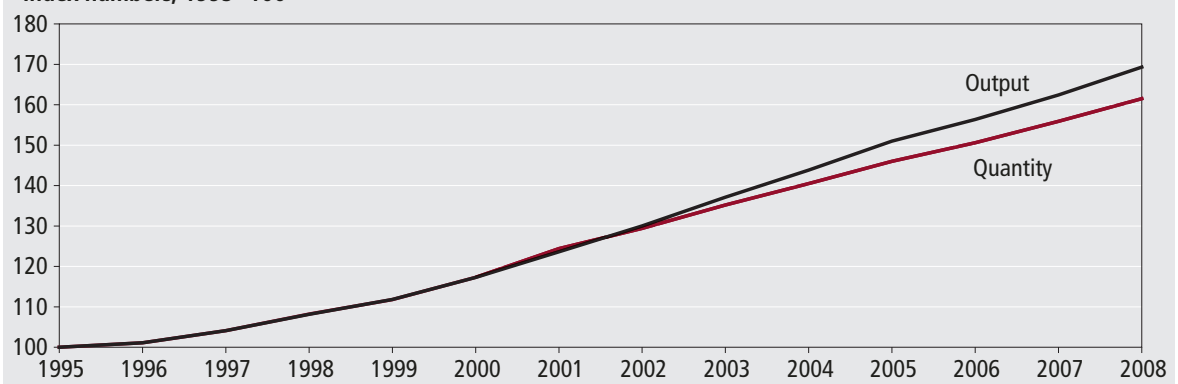

Source: Office for National Statistics

Table 1

\section{Contributors to quality-adjusted output growth, 2001-02 to 2008-09}

England

\begin{tabular}{lrrrr}
\hline & $\begin{array}{r}\text { Service is } \\
\text { responsive to } \\
\text { user needs }\end{array}$ & $\begin{array}{r}\text { Outcome } \\
\text { from primary } \\
\text { medical care }\end{array}$ & $\begin{array}{r}\text { Survival, health } \\
\text { gain and } \\
\text { waiting times }\end{array}$ & Total \\
\hline $2001-02$ & 0.00 & 0.00 & -0.09 & -0.09 \\
$2002-03$ & 0.00 & 0.12 & 1.25 & 1.37 \\
$2003-04$ & 0.02 & 0.09 & 0.64 & 0.76 \\
$2004-05$ & 0.01 & 0.12 & 1.06 & 1.18 \\
$2005-06$ & 0.00 & 0.09 & 0.72 & 0.81 \\
$2006-07$ & 0.03 & 0.06 & 0.28 & 0.37 \\
$2007-08$ & 0.03 & 0.12 & 0.29 & 0.44 \\
$2008-09$ & - & - & - & 0.44 \\
\hline Average 2001-02 to 2007-08 & 0.01 & 0.08 & 0.59 & 0.69 \\
Average 2001-02 to 2008-09 & & & & 0.66 \\
\hline
\end{tabular}

Source: Office for National Statistics

each healthcare component from 1995 to 2008.

Quality adjustments in healthcare reflect two dimensions of quality:

- the extent to which the service succeeds in delivering intended outcomes; and

- the extent to which the service is responsive to users' needs

The first dimension accounts for around 97.5 per cent of total quality change. It consists of two measures to adjust the quantity of healthcare output based on success in delivering health gain: using data on short-term survival rates, health gain following treatment in hospital and impact on health gain as a result of change in waiting times for health treatment, and outcomes from primary medical care. The second dimension accounts for the remaining 2.5 per cent of quality change and uses patient-reported outcome measures as an indicator of the responsiveness of the service to users' needs.
The main contribution to quality change came from the extent to which the service succeeds in delivering intended outcomes (short term survival rates, health gain following treatment in hospital and impact on health gain as a result of change in waiting times for health treatment), which improved by an annual average of 0.59 per cent from 2001-02 to 2007-08. Smaller contributions come from outcomes from primary medical care and responsiveness to users' needs, with an annual average improvement of 0.08 per cent and 0.01 per cent respectively over the same period (Table 1). The overall adjustment for 200809 is assumed to be the same as in 2007-08, as source data for that period will not be available until late 2010 .

The cumulative impact of quality adjustments is shown in Figure 4 on a calendar year basis. In 2008, qualityadjusted output was 7.8 index points, or 4.8 per cent, greater than quantity (unadjusted output). From 2001 to 2008, quality adjustments have added an average of 0.6 percentage points a year to output growth.

\section{Trends in inputs}

Latest estimates show that between 1995 and 2008, healthcare inputs grew by 75.1 per cent, an average annual increase of 4.4 per cent. From 2002 to 2005 inputs growth was above the average for the whole time period. More than half of overall inputs growth was accounted for by increases in the volume of goods and services inputs, despite labour accounting for the largest share of input expenditure (Figure 5).

Key changes in inputs between 1995 and 2008 include:

- 143 per cent of the volume of goods and services used in the production of health output, about half of which came from a rise in the volume of 'other' goods and services inputs. This category includes a variety of goods and services used in the provision of healthcare in both hospitals and elsewhere. For example, it includes clinical supplies used in hospitals, supplies used in GP surgeries and premises maintenance costs

- 41 per cent increase in the volume of labour, which at least partly relates to the recruitment drive following the NHS Plan (Department of Health 2000)

Healthcare inputs are divided into three broad components: labour (for example medical staff), goods and services (such as clinical supplies and electricity), and capital 
Figure 5

Growth in the volume of healthcare inputs, 1995-2008

United Kingdom

Index numbers, 1995 $=100$

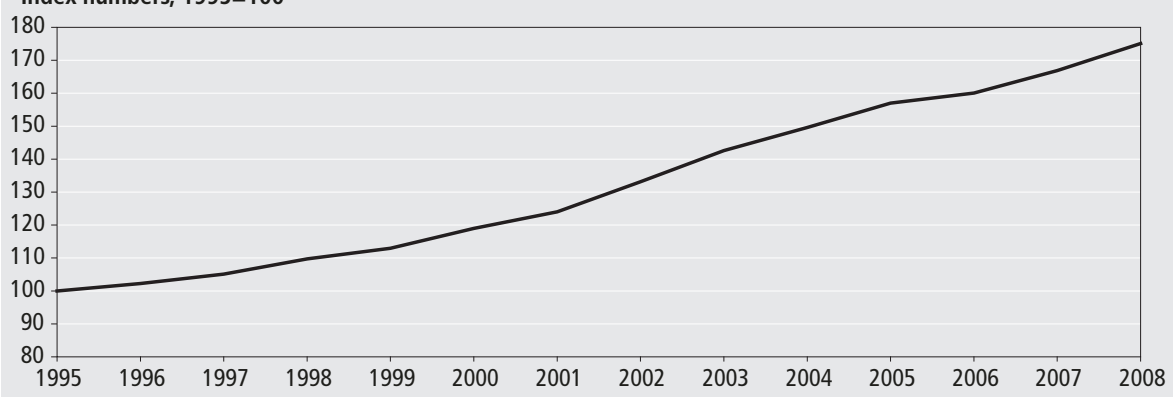

Source: Office for National Statistics

consumption, a measure of the extent to which the capital stock is used up in a given period (for example, depreciation of goods such as buildings and vehicles).

Expenditure on labour and on goods and services is measured in current prices (what was actually paid). Capital consumption in current prices is estimated using a Perpetual Inventory Model (see Dey-Chowdhury 2008).

Table 2 summarises changes in expenditure on publicly funded healthcare from 1995 to 2008 .

In 2008 expenditure on healthcare inputs was approximately $£ 102$ billion. Healthcare is the largest component of General Government Final Consumption Expenditure (GGFCE), accounting for 33 per cent of the total and accounts for around 7 per cent of the expenditure measure of Gross Domestic Product (GDP). Labour costs make up the largest component of healthcare expenditure. In 2008 current price labour expenditure was $£ 58$ billion, 57 per cent of the annual total. In 1995 labour accounted for 61 per cent of total expenditure. Goods and services expenditure accounted for 41 per cent of expenditure in 2008 ( $£ 42$ billion) in current prices. The component consists of the goods and services procured outside the NHS that are consumed in the production of healthcare services in any given year. In 1995 goods and services accounted for 35 per cent of total expenditure. The smallest inputs component is capital consumption, which in 2008 was estimated at $£ 1.8$ billion, or approximately 2 per cent of the total.

Table 3 summarises changes in the volume of healthcare inputs by component over the period 1995 to 2008. Components are weighted by their relative share of expenditure to calculate the overall index.

The volume of UK healthcare inputs grew by 75.1 per cent between 1995 and 2008, an annual average of 4.4 per cent. Between 1995 and 2001, average growth in the volume of total healthcare inputs was lower than the overall average at 3.7 per cent a year. Growth was highest between 2001 and 2003 at an average of 7.2 per cent a year; then grew less quickly between 2003 and 2008 at 4.2 per cent a year on average.

The largest component of growth in the volume of healthcare inputs was goods and services, although labour was also important. Of the 75.1 per cent increase in the total index, goods and services and labour contribute 46.7 and 27.0 percentage points respectively, while capital consumption contributes 1.4 percentage points.

\section{Further work}

ONS will continue to work with the Department of Health, the NHS Information Centre, health departments in the devolved administrations and others on a number of developments:

- improvements in coverage, the productivity measure in this article includes output and inputs data for England, Northern Ireland and Wales, although coverage for Northern Ireland and Wales is narrower than

Table 2

\section{Expenditure $^{1}$ on publicly funded healthcare inputs 1995-2008}

\begin{tabular}{|c|c|c|c|c|c|c|c|c|c|c|c|c|c|c|c|}
\hline & & & & & & & & & & & & & & & $\begin{array}{r}\text { Average annual } \\
\text { percentage }\end{array}$ \\
\hline & 1995 & 1996 & 1997 & 1998 & 1999 & 2000 & 2001 & 2002 & 2003 & 2004 & 2005 & 2006 & 2007 & 2008 & change \\
\hline Labour & 23.3 & 25.2 & 26.3 & 27.2 & 28.1 & 30.1 & 33.4 & 36.5 & 41.3 & 46.7 & 49.6 & 52.1 & 54.4 & 58.1 & 7.3 \\
\hline Goods and Services & 13.5 & 15.2 & 15.1 & 17.0 & 19.9 & 20.7 & 22.3 & 25.0 & 26.4 & 28.5 & 30.7 & 35.9 & 38.5 & 41.8 & 9.1 \\
\hline Capital Consumption & 1.2 & 1.3 & 1.4 & 1.4 & 1.4 & 1.6 & 1.5 & 1.6 & 1.8 & 1.7 & 1.8 & 1.8 & 1.9 & 1.8 & 2.9 \\
\hline Total & 38.1 & 41.7 & 42.8 & 45.6 & 49.4 & 52.4 & 57.2 & 63.1 & 69.4 & 76.9 & 82.1 & 89.8 & 94.8 & 101.7 & 7.8 \\
\hline
\end{tabular}

Note:

Source: Office for National Statistics

1 Figures are based on General Government Final Consumption Expenditure for healthcare. In the UK National Accounts, all expenditure on GP services is allocated to goods and services. For this article, estimates of expenditure on labour in GP surgeries, and expenditure on capital in GP surgeries have been calculated, subtracted from goods and services expenditure and added to the labour and capital consumption categories.

Table 3

Volume of healthcare inputs by component

\begin{tabular}{|c|c|c|c|c|c|c|c|c|c|c|c|c|c|c|c|}
\hline & & & & & & & & & & & & & & & $\begin{array}{r}\text { Average annual } \\
\text { percentage }\end{array}$ \\
\hline & 1995 & 1996 & 1997 & 1998 & 1999 & 2000 & 2001 & 2002 & 2003 & 2004 & 2005 & 2006 & 2007 & 2008 & change \\
\hline Labour & 100.0 & 101.2 & 101.7 & 103.2 & 105.5 & 108.0 & 112.3 & 118.4 & 124.4 & 130.4 & 134.8 & 135.5 & 136.4 & 141.0 & 2.7 \\
\hline Goods and Services & 100.0 & 103.0 & 108.9 & 119.4 & 123.6 & 135.1 & 142.1 & 156.8 & 173.2 & 182.0 & 197.2 & 206.4 & 226.3 & 243.1 & 7.1 \\
\hline Capital Consumption & 100.0 & 114.2 & 126.5 & 133.3 & 144.1 & 158.9 & 154.0 & 159.8 & 164.6 & 170.8 & 155.8 & 149.7 & 149.8 & 147.3 & 3.0 \\
\hline Total inputs index & 100.0 & 102.3 & 105.1 & 109.7 & 112.9 & 119.0 & 124.0 & 133.1 & 142.6 & 149.6 & 157.0 & 160.1 & 166.9 & 175.1 & 4.4 \\
\hline
\end{tabular}


for England. Future work will look into expanding coverage to include full data for these countries and also for Scotland by working closely with their respective health departments. Work will also focus on increasing the coverage of existing output measures to match more closely the activity covered by expenditure

- improvements to the quality adjustments, ONS will continue to work with Department for Health and the Centre for Health Economics at the University of York to build upon the existing quality adjustments. In particular, future work will look into replacing some of the assumptions in the survival rate calculation with real data and also into the use of new patient reported outcome measures (PROMs) data collected by the Department for Health

- improvements to the measure of the volume of inputs, ONS will shortly publish a scoping paper looking into an alternative measurement of primary care input. Since the establishment of the NHS, GPs have been contracted to, rather than being directly employed by, the public sector. The paper will present an alternative approach that considers GP expenditure as part of the intermediate consumption of the NHS, in contrast to the current treatment of GP labour, goods and services and capital consumption alongside directly publicly funded NHS activities. A period of user consultation will follow the paper's publication.

\section{CONTACT}

凶ـelmr@ons.gov.uk

\section{REFERENCES}

Department of Health (2000) The NHS Plan: a plan for investment, a plan for reform, available at:

www.dh.gov.uk/en/Publicationsandstatistics/ Publications/PublicationsPolicyAndGuidance/ DH_4002960

Dey-Chowdhury (2008) 'Methods Explained: Perpetual Inventory Model', Economic \& Labour Market Review 2(9), pp 48-52

NHS Plan (2000) A plan for investment, a plan for reform, available at: www.dh.gov.uk/en/Publicationsandstatistics/ Publications/ublicationsPolicyAndGuidance/ DH_4002960
ONS (2009a) Total Public Service Output and Productivity, June 2009, available at: www.statistics.gov.uk/cci/article. asp? ID $=2212$

ONS (2009b) Health Care Output 1995-2007, June 2009, available at:

www.statistics.gov.uk/cci/article. asp? id $=2213$

ONS (2010a) Improving the method used to calculate the volume of healthcare inputs,

February 2010, available at:

www.statistics.gov.uk/cci/article. asp? ID $=2354$

ONS (2010b) Public Service Output, Inputs and Productivity: Healthcare, available at: www.statistics.gov.uk/CCl/article. asp? ID $=2382$

ONS (2010c) Public Service Output, Inputs and Productivity: Healthcare - Extended Analysis, UKCeMGA, Office for National Statistics, available at:

www.statistics.gov.uk/CCl/article. asp? ID $=2383$

ONS (2010d) Public Service Output, Inputs and Productivity: Healthcare Triangulation, UKCeMGA, Office for National Statistics, available at: www.statistics.gov.uk/CCl/article. asp? ID =2384 